\title{
Institutional Databases, Official Statistics and Challenges of Monitoring and Evaluation in Nigeria's Public Sector
}

\author{
Chiedo Akalefu ${ }^{1}$
}

\begin{abstract}
This paper examined the impacts of non-availability and unreliability of institutional data and official statistics on the practice of Monitoring and Evaluation in Nigeria. It also examined the implications of these impacts on the assessment of public policies and national development. Findings showed that where institutional data on social indicators exist, they are either not reliable because data on indicators from different public institutions do not correspond with each other, or they are completely at variance with existing realities. This poses great challenges to effective Monitoring and Evaluation in Nigeria. Consequently, the paper amongst other things, recommended strict enforcement of mandatory digitization and data back-up devices for all MDAs in the country by outsourcing data management to private corporations, and the strengthening of institutional and resource capacities of government agencies and institutions that are saddled with the responsibility of maintaining institutional data on social indicators.
\end{abstract}

Keywords: Institutional Database, Official Statistics, Monitoring and Evaluation, Public Sector, Nigeria

\section{Introduction}

Although the concept of Monitoring and evaluation (M\&E) is a recent entrant in the literature on development and management studies, its practice however,dates back to human history and has since existed virtually in every aspect of human operationeither in our personal (domestic) engagementsor in public/governmental organizations. In ancient times, monitoring and evaluation were adopted in agricultural practices, including seed and animal selection, and evaluation of the evolution of appropriately adopted tillage systems. In recent times however, among the distinguishing features of Monitoring and Evaluation is the fact that they have become activities tied directly to specific development intervention (Edmunds \& Marchant, 2008).

Consequently, the conceptualization of Monitoring and Evaluation has been divergent and varied. Since they are disciplines that have been in a state of evolution over the past quarter century, they mean different things to different people. According to Edmunds and Marchant (2008), among the earlier attempts to situate the concept of Monitoring and Evaluation in its proper perspectives, were the Guiding Principles For The Design And Use Of Monitoring and Evaluation in Rural Development Projects and Programmes (UNATFRD, 1984). At that time, M\&E were seen primarilyas project-related activities. Twenty years after, the concepts were revised and updated by the DAC Network on DevelopmentEvaluation (2002) which on the one hand, defined monitoring as "a continuing function that uses systematic collection ofdata on specified indicators to provide management and the main stakeholders of an ongoing developmentintervention with indications of the extent of progress and achievement of objectives and progress in theuse of allocated funds." On the other hand, Evaluation was defined as "the process of determining the worth orsignificance of a development activity, policy or program ... to determine the relevance and fulfilment ofobjectives, development efficiency, effectiveness, impact and sustainability...'Thus, the essence of any organization's engagement in Monitoring and Evaluation activities is primarily to ensure compliance with set objectives of policies, programmes, and projects, in order to give feedback to relevant stakeholders. This feedback ultimately determines the next plan of action as to whether to continue or re-strategize.

In Nigeria like other Third World Countries (TWCs), Monitoring and Evaluation are relatively new practices, which have been instituted especially in the public sector to ensure effective and efficient implementation of public policies, programmes and projects aimed at ensuring good governance and accountability. Given that the success or otherwise of the process of Monitoring and Evaluation involves the interplay amongst factors such as, human and capital resources, identification of outputs and outcomes, proper implementation of set projects and the availability of reliable set of data. In most TWCs, the practice is often confronted by a myriad of challenges.

Using Nigeria as a case study, the paper seeks to examine the nature and dimension of the challenges of Monitoring and Evaluation especially in the public sector. The causes of these challenges and their implications on development were also highlighted.

\footnotetext{
${ }^{1}$ Monitoring and Evaluation Unit, National Institute for Legislative Studies, National Assembly, Abuja - Nigeria cakalefu@yahoo.com
} 


\section{Statement of the Problem}

Monitoring and Evaluation is a core practice in development and public resource management. Its essence is to ensure realization of set objectives and compliance with set targets in the implementation of development-oriented public policies, programmes and projects. In Nigeria however, achieving this fundamental essence of Monitoring and Evaluation is problematic. This arises from two major problems. First is the problem of non-availability of sets of institutional data on basic social indicators. The second problem is that, where institutional data on social indicators exist, they are either not reliable (because data on indicators fromdifferent public institutions do not correspond with each other), or they are completely at variance with existing realities. This poses an uphill task to effective Monitoring and Evaluation in Nigeria.

On the one hand,because data on social indicators are non-existent, determining baseline for those indicators becomes difficult. This sets a chain of reactions that result ultimately in inefficiency and lack of development. This is because if baselines cannot be determined, setting targets becomes difficult and without targets, outcomes become illusive and impacts cannot be measured ultimately. Consequently, public policies, programmes and projects do not meet targets nor do they achieve set objectives. On the other hand, Monitoring and Evaluation still encounter problems in cases where institutional data exist. Given that sets of data on the same indicators vary from one institution to another, their reliability becomes an issue. Dependence on unreliable data to reach conclusions and to make policy recommendations undoubtedlychallenges the validity of the outcome of Monitoring and Evaluation exercises.

The foregoing presents us with the following key questions;

1. What factors account for non-availability and unreliability of institutional data on social indicators in Nigeria?

2. How do the forgoing situations pose challenges to the process of Monitoring and Evaluations in Nigeria's public sector?

3. What are the implications of the foregoing situations on development in Nigeria?

4. Are there practical solutions to the problems of non-availability and unreliability of institutional data in Nigeria?

\section{Objective of the Study}

The general objective of this paper is to examine the challenges of Monitoring and Evaluation in Nigeria's public sector. Specifically, the paper seeks to;

i. Identify the factors that account for non-availability and unreliability of institutional data in Nigeria;

ii. Examine the impact of non-availability and unreliability of Institutional data on Monitoring and Evaluation as a core practice in development and public policy management;

iii. Examine the implication of the foregoing situations on development in Nigeria; and

iv. Recommend solutions that may contribute in addressing the problem.

\subsection{Monitoring and Evaluation}

\section{Conceptual Clarifications}

Monitoring and Evaluation is a process, through which actions, policies, programmes, goals and targets are scrutinized and assessed to determine their impact either in our personal lives, businesses or the general public. It is also a process through which public set goals are assessed in order to ascertain the level of achievement or attainment. Consequently, therefore, monitoring and evaluation is a sine qua non for any and every democracy with the goal of achieving accountability, transparency and good governance.

According to the International Federation of Red Cross and Red Crescent Societies (2011),monitoring is an ongoing process that tends to focus on what is happening. It helps to check progress, inform decisions and remedial action, update project plans, and support accountability. On the other hand, evaluations are conducted at specific points in time to assess how well it happened and what difference it made and to assess progress and worth, identify lessons and recommendations for longer-term planning, provide organizational learning and accountability.

Furthermore, it is very important to clarify that monitoring and evaluation may not be feasible without key components of which, baseline data is paramount. Although, Baseline and End line studies or data are not evaluations themselves, they are however, important part of assessing change. A better way to describe the relevance and role of Baselines in monitoring and evaluation would be to agree with Chinua Achebe in his book "There was a Country" where he espoused an Igbo proverb that; "a man who does not know where the rain began to beat him cannot say where he dried his body". Implicitly therefore, Baseline helps in understanding the current status of situation and to determine how the target will be set. Thus, in projects, programmes or policy interventions, there is need to establish concrete baseline data otherwise, the entire exercise may be void. 


\subsection{Data Availability}

The PC encyclopedia defines data availability as the degree to which data can be instantly accessed.Thus,data availability refers to the degree to which it is readily available, accessible and obtainable at all times. In this case, it becomes immaterial if the required data is quantitative; (in other words data measures and explains what is being studied with numbers) or qualitative; (which explains what is being studied with words, documented observations, representative case descriptions, perceptions, opinions of value, etc). Qualitative methods use semi-structured techniques (e.g. observations and interviews) to provide in-depth understanding of attitudes, beliefs, motives and behaviors. Data collection more often than not, is dependent upon data availability. In as much as both categories of data are reliable and acceptable in Monitoring and Evaluation, only quantitative data can be analyzed statistically, thus more rigorous assessments of the data are possible. ${ }^{1}$ Qualitative data in some instances could require further scrutiny especially when the source is either anecdotal or may have to be processed through interpreters. In this case, the possibility of distortion becomes imminent. ${ }^{2}$ Monitoring is the ongoing collection and analysis of data that informs project managers if progress toward established goals is being achieved. Evaluation is a comprehensive appraisal that looks at the long-term impacts of a project and exposes what worked, what did not, and what should be done differently in future projects. ${ }^{3}$ Nevertheless, Monitoring and Evaluation thrives in the ability of practitioners to use reliable and valid information/data in their analysis. The UNDP handbook further explains that Monitoring usually provides raw data that requires further analysis and ... they are of particular importance to large, key programmes and projects.

Given the indispensability of data in monitoring and evaluation, Kusek and Rist (2004a),have outlined eight key questions, which would serve as caveat for gathering authentic and reliable data;

1. What are the sources of data?

2. What are the data collection methods?

3. Who will collect the data?

4. How often will the data be collected?

5. What is the cost and difficulty to collect the data?

6. Who will analyze the data?

7. Who will report the data?

8. Who will use the data?

\subsection{Data Management}

Data is defined as "[a] reinterpretable representation of information in a formalized manner suitable for communication, interpretation, or processing" (Collins, 2012). Examples of data include a sequence of bits, a table of numbers, the characters on a page, the recording of sounds made by a person speaking, or a moon rock specimen." Types of data include,

- observational data;

- laboratory experimental data;

- computer simulation;

- textual analysis;

- physical artifacts or relics

In other words, resources are generated, curetted, made accessible, and preserved for subsequent needs such as research, learning, and policy activities.

\subsection{Baseline Data}

According to the World Bank Institute (2007), Baseline Data are initial information on program participants or other program aspects collected prior to the program intervention. They are essential to enable stakeholders (e.g., policymakers, beneficiaries, etc.) to monitor and track changes and be used later to provide a comparison for assessing program outcomes or impacts. The WBI goes further to enumerate the importance of baseline data. When baseline data are notavailable, it is difficult to:

- Set future targets of the project

- If you do not know where you are, how can you know where you are going?

- Estimate changes as a project proceeds in monitoring

- Compare the initial conditions and changes of project and control groups in an impact evaluation These pointers clearly highlight the inevitability of baseline data in any given Monitoring and evaluation exercise. 


\section{Presentation and Analysis of Stylized Facts}

Available of comprehensive and accurate data is the key foundation to informed policy and decisionmaking.In development and policy management, comprehensive and accurate data enable policy projections that results in practical solutions to improve strategic and tactical performance in development; identify, reduce and mitigate risk; satisfy regulatory enquiry and leverage cost savings. In a country such as the United States, population data/ statistics of an area determines the amount of school grant or government allocations especially to public school. This may have informed the assertion by Oluba(2010) and Oluba (2011) that public policy and decision-making process should be founded on strong evidence. In formed public policies, on the other hand, are products of Monitoring and Evaluation exercise, which in turn relies on accurate institutional data.

Thus, the entire range of governmental operations revolves around and underscores the critical importance of availability and reliability or accuracy of institutional data. At policy level, adequately warehoused database that are regularly and appropriately processed for information and insights should provide the basis for government'sdevelopmental policies, programmes and projects that will consistently meet public expectations. This however is not the case in Nigeria as institutional data are either not available or are unreliable for purposes of evaluating public policies, programmes and projects.

The tables below illustrate the challenges posed to Monitoring and Evaluation by problems of nonavailability and unreliability of institutional data in Nigeria with data on selected sectors, education, health and public finance.

\subsection{Educational Statistics}

Table 1: Primary School Enrolment Figures in Nigeria: 2004 - 2010

\begin{tabular}{|c|c|c|}
\hline \multirow{2}{*}{ Year } & \multicolumn{2}{|c|}{ Institution } \\
\cline { 2 - 3 } & NBS & UBEC \\
\hline 2004 & $21,395,510$ & NA \\
\hline 2005 & $22,115,432$ & NA \\
\hline 2006 & $23,017,124$ & NA \\
\hline 2007 & $21,632,070$ & $21,122,583$ \\
\hline 2008 & $21,294,517$ & $21,121,157$ \\
\hline 2009 & NA & $21,714,318$ \\
\hline 2010 & NA & $23,291,709$ \\
\hline
\end{tabular}

Sources:Author's compilation with data from National Bureau of Statistics (NBS), Universal Basic Education Commission \&Federal Ministry of Education

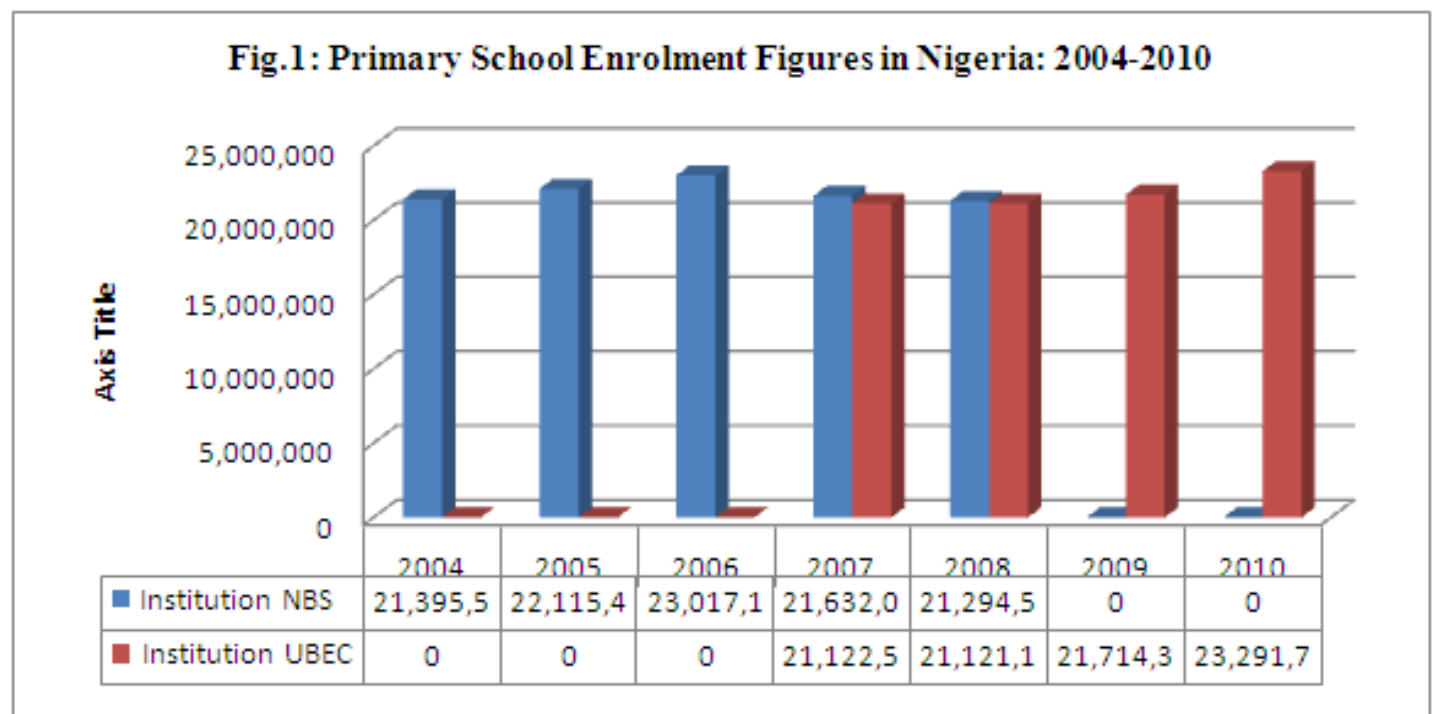

Sources: Author's compilation with data from National Bureau of Statistics (NBS), Universal Basic Education Commission \& Federal Ministry of Education

Table 1 and Figure 1 show data generated by two government institutions; National Bureau of Statistics (NBS) and Universal Basic Education Commission (UBEC), for primary school enrolment between 2004 and 2010. Out of the 7-year period sampled, NBS has figures for 5 years only (2004-2008). No figures were posted in 2009 and 2010. On the other hand, UBEC has figures for 4 years (2007-2010). No figures were posted between 2004 and 2006 . 
Simultaneously, NBS and UBEC have figures in 2007 and 2008 only. However, the figures quoted by both institutions for these 2 years are at variance with each other. In 2007, while NBS quoted 21,632,070, UBEC quoted 21,122,583. Again, in 2008, while NBS quoted 21,294,517, UBEC quoted 21,121,157. These project obvious differences in institutional data for the same sector of the society within the same period.

\subsection{Health Statistics}

Data for Table 2 and Figure 2 are sampled from two government institutions; National Agency for the Control of AIDS (NACA) and National Bureau of Statistics (NBS). For figures on People Living With HIV/AIDS (PLWHA) in Nigeria, a 10-year period (2001 - 2010) were sampled. Out of this period, NBS posted no figures for 2001, 2009 and 2010. Simultaneously, NACA and NBShave figures for 7 years $(2002-2008)$ only. However, the figures quoted by both institutions for these 7 years are at variance with each other (see Table 2 and Fig.2), which project obvious differences in institutional data for the same sector of the society within the same period.

Table 2: Projected HIV Population/PLWHA in Nigeria: $2001-2010$

\begin{tabular}{|c|c|c|}
\hline \multirow{2}{*}{ Year } & NACA & Institution \\
\cline { 2 - 3 } & $2,493,521$ & NA \\
\hline 2001 & $2,627,371$ & $3,532,335$ \\
\hline 2002 & $2,752,164$ & $3,392,802$ \\
\hline 2003 & $2,852,904$ & $3,295,862$ \\
\hline 2004 & $2,948,865$ & $3,191,203$ \\
\hline 2005 & $3,017,022$ & $3,138,854$ \\
\hline 2006 & $3,090,740$ & $3,083,007$ \\
\hline 2007 & $3,141,095$ & $3,594,087$ \\
\hline 2008 & $3,193,885$ & NA \\
\hline 2009 & $3,238,769$ & NA \\
\hline 2010 & 2ay & . \\
\hline
\end{tabular}

Sources: Author's compilation with data from National Agency for Control of AIDS

(NACA) and National Bureau of Statistics (NBS)

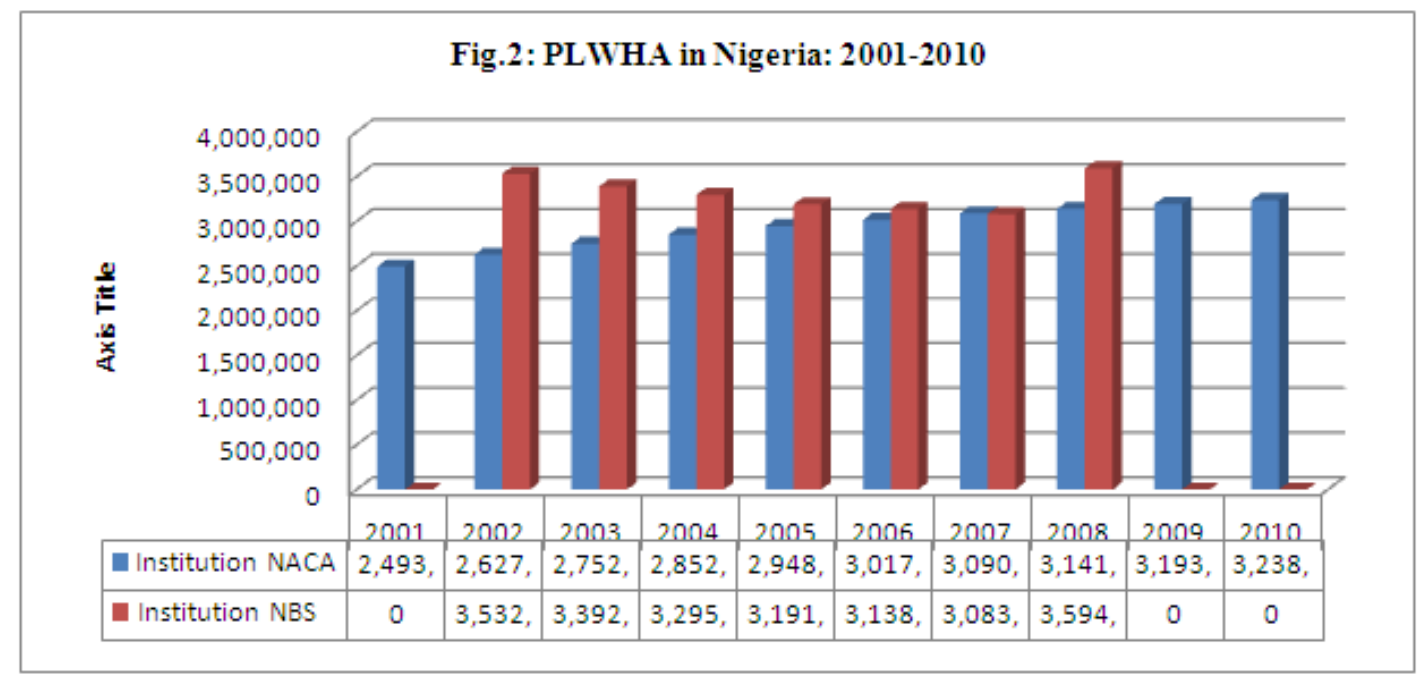

Sources: Author's compilation with data from National Agency for Control of AIDS

(NACA) and National Bureau of Statistics (NBS)

\subsection{Public Financial Statistics}

Here, we take a case of the Government revenue target in Nigeria for the year 2013. The quarterly target of Gross Federally Collected Revenue (GFCR) from 2013Q1 to 2013Q2 is N2,471.9 billion. However, official figures from the Central Bank of Nigeria (CBN) and Office of Accountant General of the Federation (OAGF) for the actual GFCR during the year differ. Actual figures from CBN for 2013Q2 to 2013Q4 differ from those of OAGF (see Table 3 and Figure 3). 
Institutional Databases, Official Statistics and Challenges of Monitoring and Evaluation in ....

Table 3: Federal Government of Nigeria Revenue Target and Performance

\begin{tabular}{|c|c|c|c|c|c|c|c|}
\hline & $\begin{array}{l}2013 \text { Quarterly Target } \\
(\mathrm{Nb})\end{array}$ & \multicolumn{2}{|c|}{ 2013Q2 (Nb) } & \multicolumn{2}{|c|}{ 2013Q3 (Nb) } & \multicolumn{2}{|c|}{$2013 \mathrm{Q} 4(\mathrm{Nb})$} \\
\hline $\begin{array}{l}\text { Gross Federally Collected } \\
\text { Revenue (GFCR) }\end{array}$ & $2,471.9$ & $2,373.7$ & $2,704.88$ & $2,746.7$ & $2,195.3$ & $2,201.9$ & $1,835.5$ \\
\hline Oil Revenue & $1,933.5$ & $1,813.8$ & $1,872.14$ & $1,622.8$ & $1,622.8$ & $1,538.4$ & $1,538.4$ \\
\hline Non-oil Revenue & 538.4 & 560 & 832.74 & $1,123.9$ & 572.5 & 663.5 & 297.1 \\
\hline Sources of Data & & CBN & OAGF & CBN & OAGF & CBN & OAGF \\
\hline
\end{tabular}

Sources: Central Bank of Nigeria (CBN) 2013Q4 Report and Office of Accountant General of the Federation (OAGF)

Figure 3: Gross Federally Collected Revenue Target and Performance

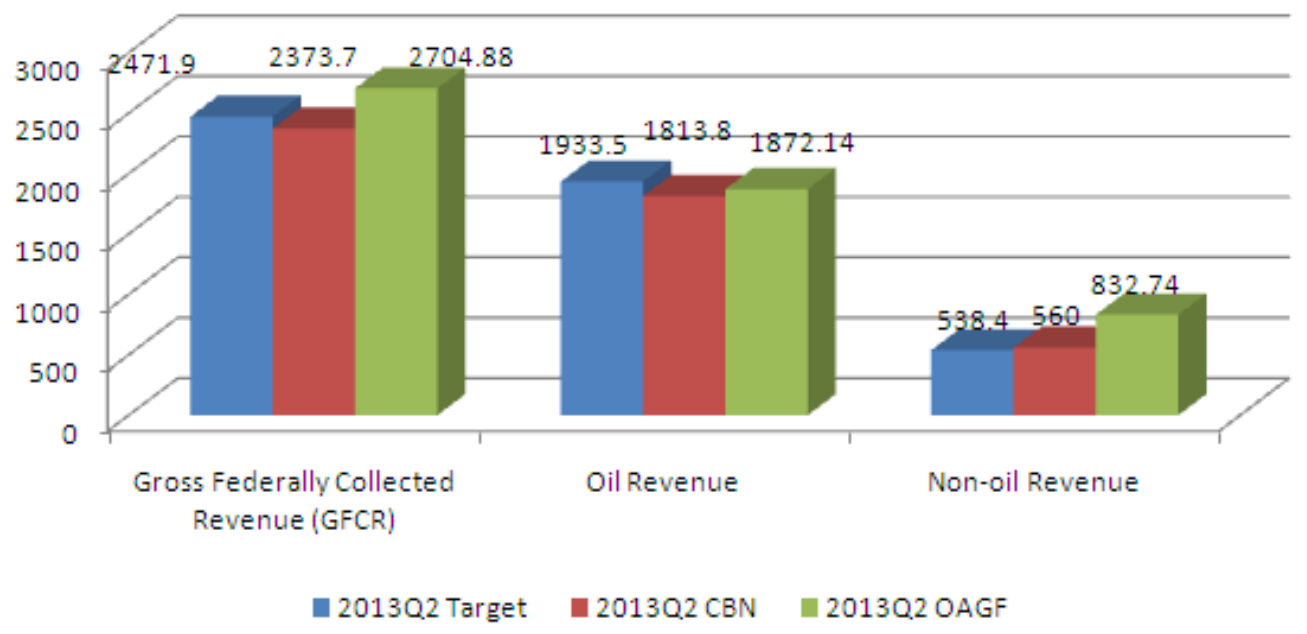

Sources: Central Bank of Nigeria (CBN) 2013Q4 Report and Office of Accountant General of the Federation (OAGF)

The official figures for oil and non-oil revenue from CBN and OAGF for 2013Q2, 2013Q3 and 2013Q4 performance are also not in agreement. This further buttress the data challenge in the Monitoring and Evaluation process in Nigeria.

\section{Discussion of Findings}

The foregoing analysis evidently shows the challenges of effective monitoring and evaluation in Nigeria's public sector. These challenges arise from the fact that in Monitoring and Evaluation, the importance of data (availability and reliability) cannot be over emphasized. For instance, assessing the impacts and outcome of Nigeria's National Policy on HIV/AIDS, AIDS Prevention Initiative in Nigeria, amongst others will require accurate data on incidence of HIV/AIDS in Nigeria, evidence of reduction or increase in the number of people living with the virus. This will help in make policy recommendations to government. The same goes for educational and housing policies. Government policies on mass housing projects for instance, must to be predicated on evidences of need, the number of people that can afford such houses and the number of persons that would be willing to purchase them, etc. The absence of such demonstrable data-based evidences will result in many housing projects ending up with the wrong demand target. When institutional data failto meet certain basic criteria such as accuracy, depth and breadth as well as timeliness, they neither help the evaluator of government policies, programmes and projects nor the government itself.

\subsection{Factors Affecting Data Availability and Reliability in Nigeria}

Edmunds and Marchant (2008) have asserted that Monitoring and Evaluation systems in developing countries, including Nigeria, face challenges because official statistics are not always available. The reason for this non-availability of official statistics is that given the fact that statistical figures were actually not in high demand either for policy purposes or for institutional use, government agencies did not see the need to develop and maintain institutional data-bases on social indicators. Secondly, awareness of Monitoring and Evaluation as necessary tool in public policy analysis in Nigeria as in other TWCs, is very low. This low level of awareness is consequent upon the fact that Monitoring and Evaluation system is a recent development in these countries. As a matter of fact, the application of monitoring and evaluation as a tool in the public sector governance in Third World Countries (TWCs) could be traced to the late 1990s, when efforts of the international development 
community to improve their evaluation activities have been in coalition with a series of initiatives to heighten aid quality and its effectiveness. Some of the initiatives include the Millennium Declaration with the adoption of the Millennium Development Goals (MDGs) in 2000, the Monterey Consensus on Financing for Development in 2002, the Rome Declaration on Harmonization in 2003, the Marrakech Memorandum on Managing for Development Results in 2004, and the Paris Declaration on Aid Effectiveness in 2005. The initiatives, alongside representatives of donor and partner countries such as Nigeria committed to align their systems and practices to accommodate the demands and directives of donor agencies towards attaining transparency and accountability and ultimately achieving project target/goals (Eni, 2008). Consequently, monitoring and evaluations was born in most developing countries where projects/ interventions for specific objectives of these initiatives existed.

This low level of awareness in Nigeria ${ }^{4}$ is evident by the fact that most government Ministries, Departments and Agencies (MDAs) do not have Monitoring and Evaluation Unit. Thus, they fail to mainstream or prominently feature monitoring and evaluation activities in their yearly budget implementation and performance. Consequently, the development and maintenance of institutional data-bases for the purpose of monitoring and evaluation system is not considered imperative.

\subsection{Implications of Non-Availability and Unreliability of Institutional Data on Development in Nigeria}

It poses a problem when Institutions of government statutorily charged with the responsibility of managing public statistics such as the National Bureau of Statistics, fall short of their responsibilities. One of the consequences is that analysts tend to avoid quoting or using figures provided by these agencies in their work. If they do at all, they compare them with those of multilateral agencies. Interestingly, these agencies often have more up-to-date information about Nigeria's state. These shortfalls compound the problem of forecasting. ${ }^{5}$ The general attitude towards Nigerian statistical data is that they are unreliable and unusable. Take for instance, the census data collections techniques, which until 2008, was still under trial stages of data capture. Since the late 1990s, Nigerian Population Commission has been inundated with proposals on various document-scanning systems. As at 2005, statements were made,suggesting that the idea of using scanning technology was utopia. The trial Census conducted in April 2005 covered about 5 per cent of the country, which translated to about 10 million of the population (Adesola, 2008).It seems almost ridiculous that in this age of and digital operations, a country such as Nigeria is floundering in technology obscurity. The gains of having a reliable and up-to-date census data is immeasurable. Apart from other socio-economic uses such as aiding the government in the design and formulation of policy frameworks, it is also used to draw the lines of legislative districts and reapportion State and District seats both at the State National Assemblies. Archival reports such as population census figures constitute important baselines for subsequent use in the Socio-economic, political and demographic dynamics in any nation.

Though efforts are being made by government to ensure the development of different databases by all government agencies and institutions, the issues of sharing remains a huge challenge, compounded by worries about the validity of the data provided by various agencies and institutions. For instance, the data generated by the National Bureau for Statistics (NBS), the Central Bank of Nigeria (CBN), Office of the Accountant General of the Federation (OAGF), amongst others show high degree of discrepancies. Yet these are Institutions saddled with the responsibility of generating data for purposes of public policy frameworks (Adepoju \& Olaomi, 2008:4).

Legislative oversight is in part, a function of the legislature and it is considered an important duty in the promotion and protection of interest of the citizens. ${ }^{6}$ Its legislative importance is found in Sections 80 and $880 \mathrm{of}$ the 1999 Constitution of the Federal Republic of Nigeria. Specifically, Section 88 provides that;

Subject to the provisions of this constitution, each house of the National Assembly shall have power to direct or cause to be directed an investigation into any matter or thing with respect to which it has power to make laws; and the conduct of affairs of any person, authority, ministry or government department charged or intended to be charged, with the duty or responsibility for (1) executing or administering laws enacted by the National Assembly and (11) disbursing or administering moneys appropriated or to be appropriated by the National Assembly (FGN, 1999).

It also goes further to state that this 'power' is conferred to enable the National Assembly expose corruption, inefficiency or waste in the executive or administration of laws within its legislative competence and in the disbursement and administration of funds appropriated(Girigiri, 2007).Furthermore, the oversight functions engages in a variety of other purposes: to keep the executive establishment responsible and accountable, to promote rationality and efficiency in the formulation and administration of public policy, to reap party advantage, and to advance the causes of individual legislators interest groups, and other stakeholders in the polity. Against this backdrop, it is perplexing that controversy brews over the issue of legislative oversight, checks and balances.

Amidst these purposes, spring one of the major challenges of Monitoring and Evaluation. Legislators tend to ignore the fact that Parliamentary Staff and Civil Servants who assist in the formulation of Policies and 
drafting legislative documents are part of the Legislature as well. The understanding would be that during oversight activities, all relevant parties (including monitoring and evaluation) involved ab initio in the process will be galvanized into action. Unfortunately, oversight visits tends to take the posture of a "familiarization jamboree" between Legislators and MDAs. The expectation naturally would be that oversight visits ought to utilize the monitoring and evaluation tools as a guide to reconcile and strike balance between established frameworks, implementation status and targets/expected outcomes of Policies, programs and projects at hand. Politicians, need to take caution not to limit the specificity of the oversight function to legislators when the functionality of this exercise ought to engage broader spectrum involving the "legislature and not only the Legislators". Most of the committees leave the obvious to pursue shadows just to intimidate their prey to bow to pressure and then look for a way out through unholy "settlement". Furthermore, it is expected that if committee members are on the job to expose corruption and inefficiency in the interest of the entire country, they ought to do so dispassionately and without exposing their personal emotion or any form of prejudice towards the investigated. On the contrary, some committee members now parade around facilities in the various departments and parastatals under their committee only to attract patronage, recognition and to acquire meal or flight tickets to choice countries of the world for personal or family pleasure. Get scholarships and job opportunities for their family members and cronies. Such compromise synchronizes with a popular Latin adage; "Beneficium acipere, libertatem est vendere" in other words, "to accept kindness is to sell your freedom. Such compromise is inimical the objectivity in a case where the Principles of M\&E has to be ethically followed. Otherwise, everyone is only wallowing in a roller-coaster of Patriotic deception without a better future for posterity

\subsection{Challenges of Non-Availability and Unreliability of Institutional Data on the Practice of Monitoring and Evaluation in Nigeria}

Thus, the paucity of accurate/reliable data, and inefficient data management in establishing baseline data in Nigeria, constitute the bane in the sustenance of practice of Monitoring and Evaluation.With the exception of the establishment of the Monitoring and Evaluation Department in the National Planning Commission (under the Presidency)in 2011, there has been no existing entity with the sole responsibility of coordinating monitoring and evaluation activities in all MDAs in Nigeria. This situation makes it difficult to recognize and appreciate the relevance of monitoring and evaluation in the system.A direct flow of the problem discussed above is the dominance of insufficiently trained monitoring and evaluation staff in most of the MDAs where there is an existing monitoring and evaluation Unit. Survey conducted in selected Ministries indicates absence of dedicated monitoring and evaluation Departments or Units. M\&E related activities are handled by Human Resource departments or distributed amongst staff who possess skeletal capacity inmonitoring and evaluation. Igbokwe-Ibeto (2012) attests to this by declaring that those in charge of project monitoring and evaluation lack motivation, understanding, ability or authority to act on evaluation measurement and comparisons of actual intervention activity, actual outcome and actual impact. Kusek and Rist (2002) support this position by affirming the need for consideration of the technical components in designing and building the Monitoring and Evaluation reporting system that can produce timely, trust worthy and relevant information on the performance of government projects and policies require a decent doze of experience, skill and real institutional capacity. At the least, the capacity for a result-basedreport ought to include: the ability to construct indicators, collect, aggregate and analyze data against indicators, baselines and targets.

The challenge therefore falls on how to decipher ways to infuse the data life cycle with the services that will enable access, evaluation and re-use over time. It is one thing to gather data and a very different thing to manage or ensure its accessibility. Proper data management is vital to its accessibility. Adedayo and Olaomi (2008) have asserted that data management is a major driving force in the on-going information technology (IT). In spite of its known benefits, data driven decision-making is seriously under siege by corrupt officials. The United States, Great Britain and other developed Countries in the West or Asia are able to manage most issues in their environment because of their "data management power". Take the United States (US) census history for example; the first census began in August 2, 1790. The statistics remains until date and has tremendously aided the U.S Census Bureau in determining the Socio-economic and Political dynamics such as rate of rural-urban/ urban-rural migrations and related developments. The availability of such information constitutes a major and indispensable tool in shaping the direction and future of a Nation. Such data will clearly tell a people who they are and where they are going as a nation. It further helps our communities determine infrastructural plans ranging from Schools, to supermarkets, and homes to hospitals. It helps the government decide how to distribute funds and assistance to States and localities. ${ }^{7}$ This is the essence of Baseline information. It stands as bases for comparisons and setting targets

Given the importance of proper documentation of all governmental transactions, operations and activities for purposes of accountability, transparency and planning, monitoring and evaluation is a major tool needed for proper checks and balances on all policies, programs and projects for which the government undertakes. The fundamental responsibility of the government is to formulate policies, set goals and targets for 
the well-being of its citizens and in order to meet with political and socio-economic mandates. It therefore becomes expedient to organize methods of measuring performance as well as gathering situation reports in order to ascertain the impacts of these policies on the citizenry. Thus, properly performed, performance measurement, assessment or evaluation constitutes a watch on government, an assurance of the public's value for money, and an essential inquiry into the effectiveness of programmes and their contribution to the public good (San \& Kwok, 2006; Hunter, 2009).

\section{Conclusion and Recommendations}

The foregoing analysis clearly indicates the importance of Monitoring and Evaluation in national development. On the other hand, Monitoring and Evaluation cannot exist and survive in isolation of available and accurate institutional data as their absence impacts negatively on both the process and recommendations of the process on national development.

In Nigeria however, the practice of effective Monitoring and Evaluation is greatly challenged by the absence of Institutional data on the one hand and unreliability of available data on the other hand. The reason for this is located in the low level of awareness of the importance of data in public sector. This has had negative implications for national development in Nigeria. There is therefore urgent need to reverse the trend. To achieve, it is imperative that the following issues are addressed;

1. The Nigeria government would have to ensure the establishment of Monitoring and Evaluation Unit in all MDAs both at the State and Federal levels;

2. The promulgation a legislative act establishing a central body for the practice of Monitoring and Evaluation in the Country should be implemented;

3. Provide adequate and commensurate funding for Monitoring and Evaluation activities in all MDAs;

4. Enforce strict and mandatory digitization and data back-up devices for all MDA in the Country by outsourcing data management to private corporation; and

5. Strengthen the institutional and resource capacities of government agencies and Institutions such as National Bureau of Statistics that are saddled with the responsibility of maintaining institutional data on social indicators.

\section{References}

[1]. Adepoju, A. \& Olaomi, J.O. (2008). An Appraisal of Statistical Data Management in Nigeria: A Case for Reliable and Effective Statistical Information. Medwell Journalshttp://www.medwelljournals.com/abstract/?doi=sscience.2008.231.234

[2]. Adesola, F. (2008), Data Capture - Processing 2006 Population Housing \& Census of Nigeria. Paper presented at UN Regional Workshop on Census Data Processing. by of the National Population Commission, Nigeria at Dar-es-Salaam, Tanzania, June, $9^{\text {th }}$ $13^{\text {th }}$ June

[3]. Collins, A. (2012). Open Access Teaching Materials for Digital Preservation (Cambridge University Library for the JISC-funded PrePARe project

[4]. DAC Network on Development Evaluation (2002), Glossary of Key Terms in Evaluation, OECD, Paris, http://www.oecd.org/dataoecd/29/21/2754804.pdf

[5]. Edmunds, R. and Marchant, T. (2008), Official Statistics and Monitoring and Evaluation Systems in Developing Countries: Friends or Foes? The Partnership in Statistics for Development in the $21^{\text {st }}$ Century (PARIS21)

[6]. Eni, H. (2008), Tackling Nigeria's Data Racket (2013). Tell Magazine, February, 4, 2013 No5Evaluation handbook for ODA loan projects: JBIC Project Development Department Development Assistance Operations Evaluation Office. 2008

[7]. Federal Government of Nigeria (FGN) (1999), Constitution of the Federal Republic of Nigeria, Abuja: Government Press

[8]. Girigiri, G.K. (2007), Point of Law: Implications and Complications of Legislative Oversight Function in Nigeria. The Newswriter, http://www.thenewswriterng.com/?p=2814

[9]. Hunter, J (2009) Monitoring and Evaluation: Are We Making a Difference? Namibia Institute for Democracy

[10]. Igbokwe-Ibeto, C.J. (2012). Issues and Challenges in Local GovernmentProject Monitoring and Evaluation in Nigeria:The Way Forward. European Scientific Journal (ESJ). Vol 8, No 18

[11]. International Federation of Red Cross and Red Crescent Societies (2011), Project/Programme Monitoring and Evaluation Guide, Geneva

[12]. Kusek, J.Z and Rist, R.C. (2004) Ten Steps to a Results-Based Monitoring and Evaluation System. The World Bank, Washington, D.C.

[13]. Kusek, J.Z and Rist, R.C. (2002). Building Results-Based Monitoring and Evaluation System: Assessing Developing Countries Readiness. The World Bank, Washington, D.C.

[14]. Oluba, M.(2010), Africa's PublicPolicyChallenge: Why AppropiatePoliciesarenot Adopted; The Entreprenaur,May 18,

[15]. Oluba, M. (2011), Nigerian Management Without Data. Businessday, $11^{\text {th }}$ April 2011

[16]. San, T.S. and Kwok, A. (2006), Developing Key Performance Indicators for Effective Governance, Ethos 8, 8-13, January

[17]. United Nations ACC Task Force on Rural Development, Panel on Monitoring and Evaluation (1984), Guiding Principles for the Design and Use of Monitoring and Evaluation in Rural Development Projects and Programmes, ACC Task Force, Monitoring and Evaluation Publications, Rome.

[18]. World Bank Institute, (2007) Monitoring \&Evaluations for Results: Reconstructing Baseline Datafor Monitoring \& Evaluation-Data Collection Methodhttp://siteresources.worldbank.org 


\section{Notes}

${ }^{1}$ See glossary terms in Monitoring and Evaluation; CIVICUS. By Janet Shapiro. P. 48

${ }^{2}$ See Qualitative and Quantitative Data http://web.cortland.edu/andersmd/stats/qual.html

${ }^{3}$ Seehttp://commdev.org/monitoring-evaluation

${ }^{4}$ Average Interview response conducted from fifteen MDAs in Nigeria

${ }^{5}$ See Policy Formulation and the Scarcity of Data. BusinessDay Editorial. June 30 ${ }^{\text {th }}, 2009$. Http://businessdayonline.com/2009/06/policyformulation-and-the-scarcity-of data/
${ }^{6}$ Implications
and
Complications
of Legislative
Oversight
Function
in
Nigeria.

http://www.nationalnetworkonline.com/VOL7/vol9n16/column.html

${ }^{7}$ See U.S. Census Bureau. Available at www.census.gov 